\title{
RAZGLEDI
}

\section{GEOGRAFSKI OPUS RUDOLFA BADJURE}

\author{
AVTORJA \\ Matjaž Geršič \\ Znanstvenoraziskovalni center Slovenske akademije znanosti in umetnosti, Geografski inštitut Antona Melika, \\ Gosposka ulica 13, SI - 1000 Ljubljana, Slovenija \\ matjaz.gersic@zrc-sazu.si
}

\section{dr. Blaž Komac}

Znanstvenoraziskovalni center Slovenske akademije znanosti in umetnosti, Geografski inštitut Antona Melika, Gosposka ulica 13, SI - 1000 Ljubljana, Slovenija

blaz.komac@zrc-sazu.si

DOI: $10.3986 / G V 86205$

UDK: 91:929Badjura $R$.

COBISS: 1.02

\section{IZVLEČEK}

\section{Geografski opus Rudolfa Badjure}

$V$ članku je predstavljeno delo Rudolfa Badjure na širšem področju geografije. Poznani so predvsem njegovi turistični vodniki, nekoliko manj pa knjiga Terenska geografija, v kateri je zbral številne zemljepisne izraze, pomembna pa je tudi z vidika zemljepisnega imenoslovja. Pomembno je njegovo raznotero kartografsko gradivo, v katerem se, predvsem skozi rabo zemljepisnih imen, zrcali njegova domovinska zavest. Čeprav je bil le amaterski zbiralec gradiva, je bil, kljub nekaterim kritikam strokovnjakov, med strokovnjaki zelo cenjen. Njegova dela so pogosto temelj za razreševanje terminoloških vprašanj, številna stara zemljepisna imena pa so se ohranila verjetno tudi po njegovi zaslugi ter njegovem vztrajnem nasprotovanju tujejezičnim imenom in strokovnim ustreznicam.

\section{KLJUČNE BESEDE}

Rudolf Badjura, geografija, imenoslovje, terminologija, vodniki

\section{ABSTRACT}

\section{The complete geographical works of Rudolf Badjura}

The article gives an overview of Rudolf Badjura's work in the broader area of geography. His guidebooks in particular are well known, as is, to a lesser extent, his book Terenska geografija (»Field Geography"), a collection of numerous geographical terms which is also important from a geonomastic perspective. In addition, he produced a significant volume of cartographical material which reflected his patriotic consciousness, especially through his choice of geographical names. Although only an amateur collector, and despite some academic criticism, he was highly distinguished among experts. His works often serve as a basis for solving terminology questions, and it appears that a number of old geographical names have been preserved to this day thanks to his persistent opposition to the use of foreign names and technical equivalents.

\section{KEY WORDS}

Rudolf Badjura, geography, onomastics, terminology, guidebooks

Uredništvo je prispevek prejelo 10. junija 2014. 


\section{Uvod}

Rudolf Badjura je znan predvsem kot turistični in športni pisatelj, referent za turizem in zbiralec krajevnih znamenitosti (Slovenski biografski leksikon 1925-1991), ne zasledimo pa ga navedenega kot geografa, kar je verjetno posledica tega, da je svoje temeljno geografsko delo izdal več deset let po zaključku redakcije zvezka biografskega leksikona, $v$ katerem je omenjen.

$\mathrm{V}$ visokošolskem učbeniku z naslovom Uvod v geografijo je Badjura sicer omenjen kot geograf amater, ki se je poleg Henrika Tume ukvarjal s toponomastiko, njegovo delo Ljudska geografija pa najdemo tudi med seznamom literature s tematiko toponomastike (Vrišer 2002). Vendar tudi to očitno ne zadostuje, da bi Badjuro in njegov prispevek h geografiji, geografi bolje poznali, kar velja še zlasti za mlajše generacije.

\section{Ljudska geografija}

Delo, s katerim si Badjura zasluži prostor v slovenski geografiji, je zagotovo Ljudska geografija Terensko izrazoslovje. V njem Badjura spretno prepleta dve vodilni ideji. Prva je slovensko strokovno geografsko izrazje, predvsem za površinske oblike, druga pa geografsko imenoslovje. Vsebina je razdeljena na šest vsebinsko zaokroženih poglavij. Prvo govori o ravninskih površinskih oblikah (raven svet, ravnina), drugo o reliefnih oblikah v gričevju in gorovju (vzvišen svet, višavje), tretje je namenjeno konkavnim reliefnim oblikam (poglobljen svet, vdrtine), četrto vodovju, peto "površinski odeji«, zadnje pa govori o komunikacijah (občila). Knjiga vsebuje tudi več kot 200 skic (»črtežev«) in fotografij, ki mnoge obravnavane pojme dodatno ponazarjajo. Obe vodilni ideji se prepletata pri vsakem obravnavnem strokovnem pojmu. Njegovemu pojasnilu sledijo imenoslovni primeri (Badjura 1953). Knjiga

Slika 1: Rudolf Badjura (1881-1963).

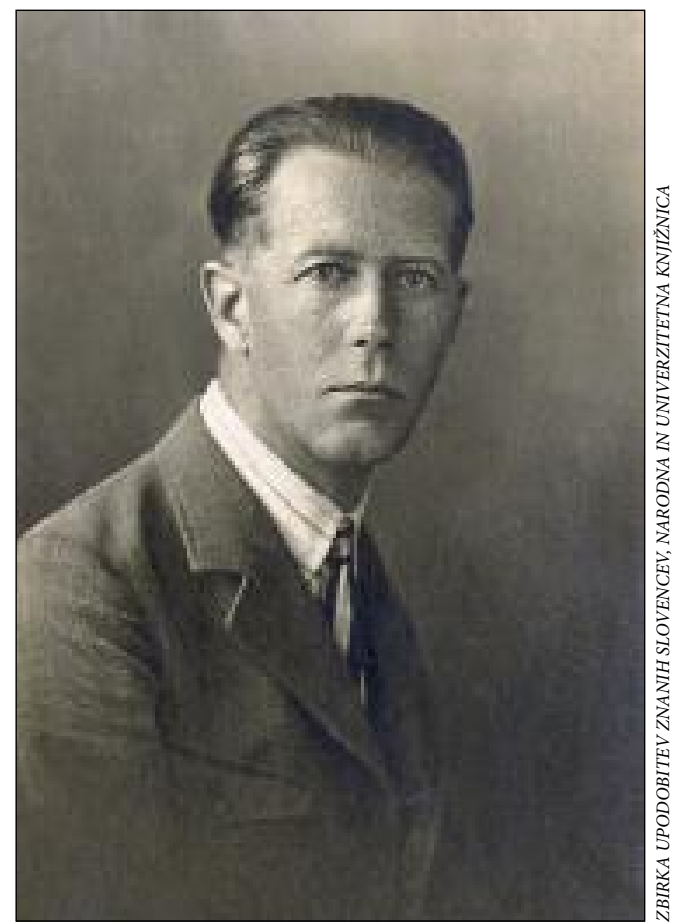


je tako hkrati geomorfološki učbenik in terminološki slovar, obenem pa eno temeljnih imenoslovnih del, ki je zdajšnjim raziskovalcem v veliko pomoč pri raziskovanju krajevnih, ledinskih in ostalih zemljepisnih imen. Vsebuje 5229 strokovnih izrazov in zemljepisnih imen, med katerim mnogi niso več $\mathrm{v}$ uporabi, bodisi zvenijo arhaično bodisi so označeni z drugim kvalifikatorjem ali pomensko niso ustrezni.

Med uveljavljenimi izrazi lahko omenimo deber, delta, dolič, globel, gorica, gramoz, meander, okljuk, ronek, rut, vrtača, med tistimi, ki pa se niso "prijeli« lahko izpostavimo nekaj značilnih primerov. Izraz žandarm (Badjura 1953, 143) uporablja za priostreno stolpasto vzpetino vendar v sodobnem izrazju te besede ne najdemo več. Podobno je z izrazom zibe (Badjura 1953, 258), ki označuje močvirna tla. Izraz vodina (Badjura 1953, 226), ki je v Slovarju slovenskega knjižnega jezika označen s kvalifikatorjem za narečno besedišče, v prekmurskem narečju pomeni '(velika) voda' (Slovar slovenskega knjižnega jezika 2000), uporablja kot obče veljaven izraz za »vodno maso«. Kot primer pomenske spremembe je izraz var (Badjura 1953, 248), ki označuje zelo fin sediment, tudi mulj; Geografski terminološki slovar (Kladnik, Lovrenčak in Orožen Adamič 2005) ga ne navaja, v Slovarju slovenskega knjižnega jezika (2000) pa pomeni bodisi "strjen material, ki je pri varjenju zmehčan ali staljen « oziroma »enoto za merjenje jalove moči električnega toka«.

Badjurova knjiga je med geografi močno odmevala. Številni so postregli z bolj ali manj konstruktivnimi kritikami (več v poglavju 5). Badjura se je na kritike odzval in leta 1957 napisal drugi del knjige, ki ga je podnaslovil Rešeto umetnih in ljudskih zemljepisnih izrazov (Badjura 1957). V njem je Badjura poleg argumentiranih odgovorov na kritike Ljudske geografije podal in pojasnil tudi mnoge popravke napak, ki so se vrinile v prvo knjigo. Za drugo knjigo Badjura ni našel založnika, zato je bila izdana le v tipkopisu. Zaradi tega odziva na drugo knjigo v stroki skorajda ni bilo.

Po desetih letih od izida prvega dela Ljudske geografije je Badjura za tisk pripravil še tretji del z naslovom Krajepisno gradivo - dodatki k Ljudski geografiji 1953 (Badjura 1963). V njem je Badjura še izpopolnil

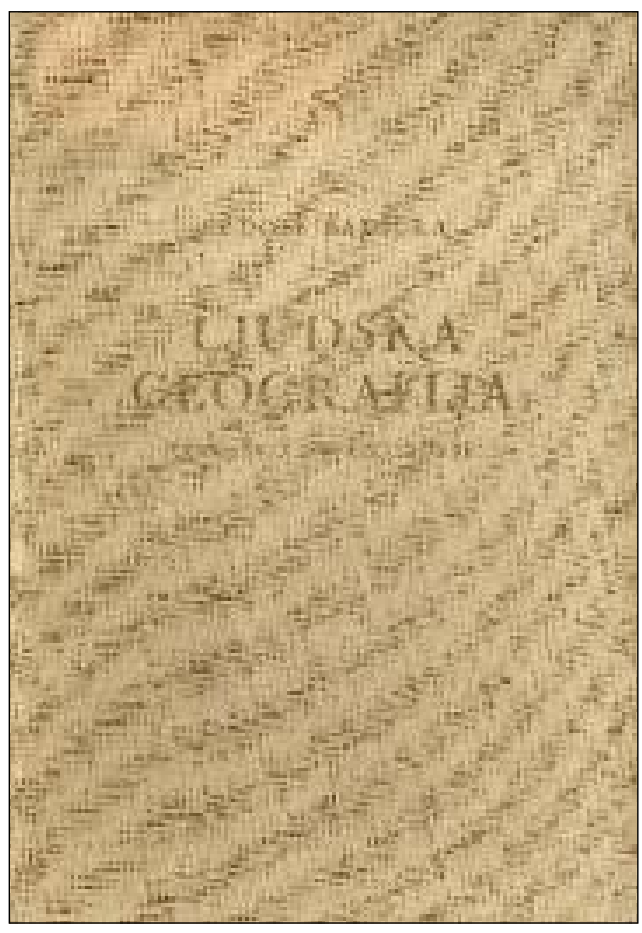

Slika 2: Naslovnica knjige Ljudska geografija Terensko izrazoslovje (1953). 
in dodatno pojasnil nekatere geografske strokovne izraze, ki se nanašajo na prvi dve deli ter na tipkopis Topografični oris 430 gorskih prehodov po Sloveniji (Badjura 1955a), podal pa je tudi nekatere popravke iz omenjenih del. Glavni namen je kot sam pravi: »... da še enkrat opozorim bralce na izredno bogastvo in lepoto naših krajevnih in ledinskih imen ... " (Badjura 1963, 5). Tudi tretje Badjurovo delo iz sklopa Ljudske geografije žal ni bilo izdano in je ostalo v tipkopisu. Tovrstne izdaje so dosegle zelo ozek krog bralcev in tako niso imele večjega vpliva na morebitne spremembe pri rabi krajevnih in ostalih zemljepisnih imen ter strokovnih izrazov.

\section{Gorski prehodi v luči geografije}

Badjura je s posebno natančnostjo in zavzetostjo preučeval gorske prelaze in njihova poimenovanja. Zmotilo ga je dejstvo, da se je v slovanski terminologi uveljavil izraz sedlo, kar je po njegovem prepričanju prevod nemškega izraza der Sattel. Na podlagi lastnih opazovanj je trdil, da pojem sedlo v slovenskem pomenu tradicionalno označuje popolnoma drugo stvar, kot jo nemška beseda. V povezavi s to tematiko je objavil tri dela, leta 1950 članek Slovensko in nemško geografsko sedlo (Badjura 1950), leto pozneje samostojno knjižico Gorski prehodi v luči ljudske geografije (Badjura 1951), nekaj let pozneje pa še tipkopis Topografični oris 430 gorskih prehodov v Sloveniji (Badjura 1955a).

V prvem prispevku pojasnjuje, da naj bi v slovenskem jeziku sedlo tradicionalno pomenilo prostor na planini, kjer so se ustalili pastirji s svojimi čredami in si postavili kolibe, ali pa izpostavljeno mesto, koder so lahko sedeli in opazovali živino. Sedlo pa, kot trdi Badjura, v nekaterih obljudenih gorskih krajih pomeni tudi zemljiški delec. Namesto izraza sedlo Badjura navaja kar 27 različnih ljudskih izrazov, ki bi jih lahko uporabljali za poimenovanje gorskih prelazov. Na podlagi natančne analize zgodovinskih virov od Valvazorja dalje zaključi, da "... sedla in podobna pri nas sedaj za gorske prehode udomačena navlaka, vse to torej ni bila od nekdaj naša narodna last! « in da »... sedlo ni pravo jugoslovansko prevalsko ime in da zato nima domovinske pravice niti pri južnih, niti pri severnih Slovanih."V topografskem delu članka Badjura najprej navede 33 toponimov, ki vsebujejo besedo sedlo, in po njegovem prepričanju niso pravilna, zato za vsak primer doda tudi pravilno poimenovanje, tako na primer za toponim Kamniško sedlo predlaga rabo imena Jermanova vrata, za Dolško sedlo Zdolška škrbina, za Bašeljsko sedlo pa Bašeljski vrh. V nadaljevanju navede 38 toponimov, kjer je po njegovem prepričanju beseda sedlo primerno uporabljena tako na slovenskem kot tujem ozemlju. Na koncu prispevka oceni, da je stanje, kjer so stari slovanski izrazi za prelaze zamenjani s pojmom sedlo »nevzdržno« in da je »... taki zmešnjavi treba napraviti konec čim prej «. Prepričan je, da »... naloga naše geografske znanosti je in mora biti, da domače dobre geografske izraze in imena določi, drži in zaščiti, ne pa da jih zanemarja in nadomešča s tujimi, nepravilnimi ..." (Badjura 1950, 170).

V samostojni publikaciji (Badjura 1951) je predhodno razpravo poglobil in dopolnil. Uvodnemu delu sledijo predstavitev geografske kategorizacije gorskih prehodov, imenoslovna tipizacija prevalskih izrazov, na koncu pa še poglavje o prevalskih topografskih imenih. $Z$ omenjeno knjižico pa Badjurovo raziskovanje gorskih prehodov in prelazov ni bilo končano. Pripravil je gradivo za knjigo Topografski oris 430 gorskih prehodov $v$ Sloveniji (Badjura 1955a), a je žal ostalo v tipkopisu. Edini javno dostopni izvod tega gradiva hrani Centralna biblioteka SAZU. Namen »... tega zadnjega prevalnega spisa ... « je bil predstaviti metodologijo zbiranja gradiva o gorskih prehodih za vse pokrajine v Sloveniji zaradi izdelave imenika, ki ga bodo lahko uporabljali strokovnjaki in širša javnost in naj bi omogočil poenoteno rabo imen gorskih prehodov (Badjura 1955a, 5).

Badjurova vztrajnost pri zavračanju besede sedlo pa je očitno temeljila na trhli podlagi. Sodobna etimologija namreč pojasnjuje, da beseda sedlo izhaja iz praslovanščine in je izpeljana iz praindoevropskega korena ${ }^{*}$ sed- v pomenu 'sedeti'. Iz praslovanske besede pa je izposojena tudi starovisokonemška beseda satul, iz katere je izpeljan sodoben nemški izraz Sattel (Snoj 1997, 557). Sklenemo torej lahko, da je resnica ravno obratna, kot je trdil Badjura. 
Kar se tiče samega pomena besede sedlo, jo v sodobnem času razumemo kot "pripravo za sedenje, prenašanje, ki se namesti živali na hrbet « ali pa kot »širši zložnejši prehod čez gorsko sleme iz ene doline v drugo" (Slovar slovenskega knjižnega jezika 1985, 612). Pomenov, kot jih navaja Badjura, Slovar slovenskega knjižnega jezika ne vsebuje, kar pa seveda ne pomeni, da v preteklosti med ljudmi niso bili prepoznani.

\section{Turistični vodniki}

Med laično javnostjo je bil Badjura gotovo najbolj poznan po številnih vodnikih. Prvi v njegovem opusu je vodnik Na Triglav, v kraljestvo Zlatorogovo! iz leta 1913, ki opisuje vzpon na najvišjo slovensko goro, takrat še znotraj avstro-ogrske monarhije (Badjura 1913a).

Preden pa je vodnike objavil kot samostojne publikacije, je svoje prispevke, opremljene z opisi poti in fotografijami, objavljal v revijah in časopisih (Brilej 1952, 43). Med letoma 1908 in 1910 je v reviji Dom in Svet predstavil Okrešelj v Savinjskih Alpah (Badjura 1908), Križno jamo pri Grahovem (Badiura 1909a) ter zimski vzpon na Veliko planino nad Kamnikom (Badiura 1909b). Med letoma 1908 in 1927 je zapise objavljal tudi v Planinskem vestniku. Tam je pisal o izletu na Kamniško sedlo (Badiura in Brinšek 1908a), novih jamah v Cerkniškem jezeru (Badiura in Brinšek 1908b), zimskih vzponih v Kamniške planine (Badiura 1921) in vzponu na Šmarnogorsko Grmado (Badjura 1927).

Leta 2009 je o Badjurovih vodnikih Stane Kocutar pripravil razstavo in razstavni katalog v Pokrajinskem arhivu v Mariboru. Predstavil je Badjurovo življenje in delo, natančneje sedem izbranih vodnikov, poleg tega pa tudi druga Badjurova dela, na primer smučarsko terminologijo. Kocutar na koncu Badjuro označi kot enega pionirjev snovanja slovenske turistične publicitete (Tovšak 2010, 187-188).

Rudolf Badjura je leta 1923 Ministrstvu za industrijo in trgovino v Beogradu posredoval željo po zemljevidih in vodnikih, ki jo je podkrepil s predlogom o petnajstih vodnikih, med katerimi naj bi nekateri izšli v več jezikovnih različicah, poleg slovenske tudi češki, nemški in srbohrvaški (Kocutar 2009, 10).

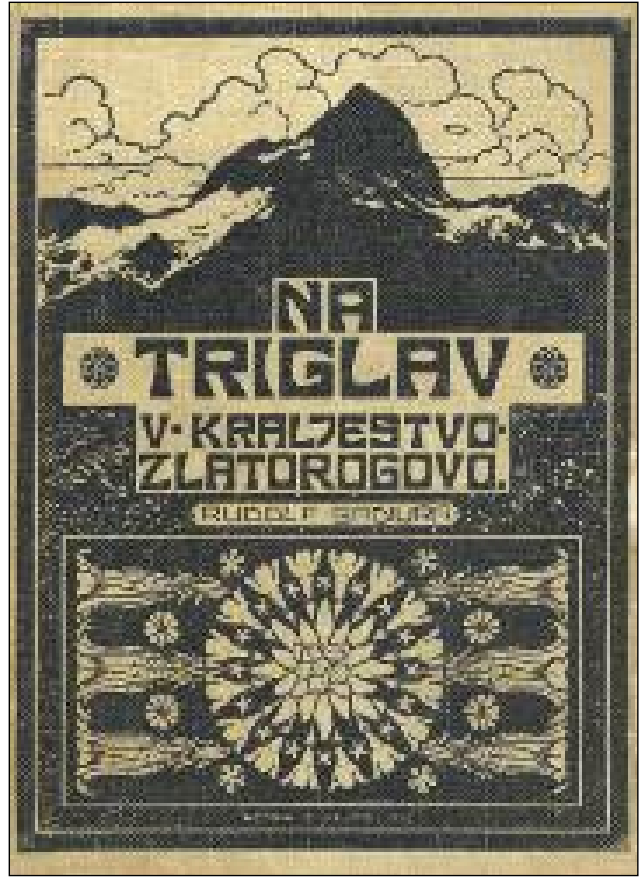

Slika 3: Naslovnica prvega Badjurovega turističnega vodnika iz leta 1913 z naslovom $\mathrm{Na}$ Triglav, v kraljestvo Zlatorogovo! 
Analiza izdanih Badjurovih vodnikov je pokazala, da končni rezultat malenkostno odstopa od njegovih načrtov; jezikovnih različic posameznih vodnikov je nekoliko manj, številčno pa jih je več, tako da lahko zaključimo, da je zbirka vsebinsko bogatejša, saj pokriva širše območje, kot si ga je Badjura sprva zastavil.

Rudolf Badjura je v svojih knjigah predstavil celotno ozemlje Slovenije z izjemo Primorja, ki je v tistem času spadalo pod Italijo, in Koroške, ki je po plebiscitu leta 1920 postala del Avstrije (Kocutar 2009, 11).

Preglednica 1: Seznam Badjurovih turističnih vodnikov (Vir: COBISS).

\begin{tabular}{rlcl}
\hline & naslov & leto & jezik \\
\hline 1 & Na Triglav, v kraljestvo Zlatorogovo! & 1913 & slovenski \\
2 & Klopinsko jezero & 1920 & slovenski \\
3 & Vrbsko jezero & 1920 & slovenski \\
4 & Ilustrovani kažipot: Ljubljana - Gorenjsko & 1920 & slovenski \\
5 & Praktični vodić: Jugoslovenske Alpe & 1922 & srbohrvaški \\
6 & Na Triglav, u kraljestvo Zlatorogovo! & 1922 & srbohrvaški \\
7 & Pohorje & 1924 & slovenski \\
\hline 8 & Kleinen führer durch Slovenien & 1925 & nemški \\
9 & Kozjakovo pogorje (nad Dravo) & 1927 & slovenski \\
10 & Zasavje & 1928 & slovenski \\
11 & 100 izletov po Gorenjskem, Dolenjskem in Notranjskem & 1930 & slovenski \\
12 & Izleti po Karavankah & 1932 & slovenski \\
13 & Zimski vodnik po Sloveniji & 1934 & slovenski \\
14 & Čez Polževo na Dolenjsko & 1935 & slovenski \\
15 & Blejski izleti & 1935 & slovenski, \\
& & & nemški, češki \\
16 & Kleinen führer durch Slowenien & 1936 & nemški \\
17 & Izbrani izleti po Gorenjskem, Goriškem, Notranjskem, & 1953 & slovenski \\
& Dolenjskem in Zasavju & & \\
\hline
\end{tabular}

Večina Badjurovih vodnikov je manjšega, žepnega formata. Vsebinsko so običajno razdeljeni na splošni del, v katerem so bralcu na voljo splošne informacije o posamezni pokrajini in njenih značilnostih, vozni redi avtobusov in vlakov, pregled letovišč in zdravilišč, ter na, kot ga Badjura imenuje, topografski del, kjer so navedene različne smeri, vzdolž katerih so natančneje opisani kraji in ostale zanimivosti v pokrajini. $\mathrm{Z}$ današnjega zornega kota imajo veliko vrednost tudi Badjurovi krajevni seznami na koncu posameznih knjižic. Ti nam omogočajo toponimske raziskave slovenskih in tujih zemljepisnih imen. Večini vodnikov so priloženi tudi zemljevidi, na katerih se izkazuje Badjurova skrb za natančen prikaz značilnosti v pokrajini, pomembnih za turizem, predvsem poti, prenočišč in drugih turističnih objektov. Badjura je bil zelo dosleden tudi pri uporabi slovenskih zemljepisnih imen na območju sosednjih držav, predvsem Avstrije in Italije.

Nekatera Badjurova vodniška dela niso bila izdana. Brilej $(1952,44)$ v članku ob Badjurovi sedemdeseti obletnici piše, da je že leta 1927 dokončal vodnik z naslovom Gornji Jadran od Sušaka do Šibenika, a ga ni uspel objaviti, pripravljeno pa naj bi bilo tudi gradivo za vodnik po Karavankah od Pece do Plešivca. Želel je napisati tudi vodnik po slovenskem Primorju.

\section{Badjura in njegovo delo $v$ očeh geografov}

Prvi odmev na Badjurovo delo v literaturi zasledimo leta 1932. Anton Melik, takrat docent na ljubljanskem oddelku za geografijo, je v Geografskem vestniku v rubriki Književnost objavil poročilo 
o Badjurovem vodniku z naslovom Izleti po Karavankah. Poleg kratkega splošnega opisa knjižice, ki jo avtor označuje kot »kažipotno knjigo«, poudarja tudi Badjurove ugotovitve pri nerešenih toponimskih vprašanjih tega dela gorskega sveta ter čezmejni značaj vodnika, saj, kot navaja »... obsega knjižica popis izletov $v$ vseh Karavankah, na obeh straneh državne meje, kakor pač ne more biti drugače. "Melik svoj prispevek sklene s pojasnilom, da so tovrstne knjige nujno in neobhodno potrebne, posebej za razvoj »tujskega prometa« (Melik 1932, 152-153).

O Badjurovi knjigi Gorski prehodi v luči geografije je v isti reviji leta 1952 pisal geograf Cene Malovrh. V kratkem članku je pojasnil koristi, ki jih ima od knjige geografska stroka, hkrati pa opozoril, da je antropocentrični pogled na določene pojave na površju zelo površen in jih je nujno treba obravnavati $\mathrm{z}$ vzročno-posledičnega vidika. Omenil je tudi Badjurove predloge pri kartografskem označevanju prevalskih oblik. Večina se mu jih je zdela primernih, pri nekaterih pa je izrazil pomisleke. Na koncu je ocenil, da ima knjižica bogato vsebino in koristno gradivo za nadaljnjo obravnavo tovrstne tematike (Malovrh 1952, 214-215).

Največji odmev med geografi na Badjurovo delo je mogoče zaslediti po izidu Ljudske geografije (Badjura 1953). V reviji Naši razgledi je še istega leta o njej kritično pisal Ivan Gams, takrat zaposlen na Inštitutu za geografijo SAZU. Gams najprej omenja odmevnost Badjurove knjige in številne pohvale, ki jih je bilo mogoče zaslediti v dnevnem časopisju. Nadaljuje s pohvalo Badjurovega prispevka k izrazoslovju in namerah po večji vlogi slovenskega izrazja v znanosti. V osrednjem delu članka Gams polemizira o posameznih izrazih, ki jih Badjura uvaja v geografsko izrazoslovje. Najprej omeni, da tudi naslov ni najbolj primeren, saj pojme, ki jih vsebuje knjiga, uporabljajo tudi geografiji sorodne stroke, na primer geologija in hidrologija. Nato kritično pretrese tudi odstavek na strani 16 in posamezne izraze temeljito pojasni. Na koncu ugotovi, da se od dvanajstih obravnavanih izrazov brez pomislekov lahko sprejmejo le trije. Svetuje previdnost pri izbiri pojmov, pojasnjuje razlike med njimi v različnih narečnih govorih (kot primer navaja pojem vrtača/dolina), sprašuje pa se tudi o smiselnosti zahtev po uvajanju starih gorskih imen za nekatere vrhove (na primer Uršlja, Plešivec). Na koncu prispevka ponovno pohvali Badjurovo delo pri zbiranju strokovnih izrazov in doda, da bi jih morala obravnavati terminološka komisija pri SAZU ter ob sodelovanju s slavisti in strokovnjaki s posameznih področij sestaviti zadovoljivo terminologijo. Glede na okoliščino, da je Badjura gradivo zbiral v prostem času, Gams zaključi, da »... gre takim ljudem, kot je v ljudskem izrazoslovju na primer Badjura, polno priznanje« (Gams 1953, 10-11). $\mathrm{Na}$ začetku leta 1954 je Badjura v Naših razgledih objavil odgovor na Gamsovo kritiko. Gamsu očita predvsem, da je »... izbral za svoj glavni predmet tisti odstavek na str. 16, kjer so zgoščeni najhujši očitki sodobnemu geografskemu pisanju«, pri čemer ni natančno pojasnil, kateri izrazi so zadovoljivi in kateri ne. V nadaljevanju na vsak Gamsov očitek odgovarja z argumenti. Očita mu tudi, da se ne zavzema dovolj za originalna slovenska imena ter za odpravo napak, ki so nastale pri rabi zemljepisnih imen, predvsem gorskih (Badjura 1954a, 9).

Leta 1953 je o Badjurovi knjigi v Slovenskem etnografu v rubriki Knjižna poročila in ocene poročal Valter Bohinec, takrat zaposlen v Narodni in univerzitetni knjižnici v Ljubljani. Zanimivo je, da Bohinec knjigo ocenjuje $\mathrm{z}$ etnografskega vidika, čeprav je bil v prvi vrsti geograf. V uvodu opiše veličino dela, ki ga je Badjura pripravil samostojno, poudari pomen ljudskih zemljepisnih izrazov in nadaljuje z njegovim pomenom za etnološko in etnografsko stroko. Sledi krajši sistematični oris knjige, pri čemer tako kot Gams ugotavlja, da je njena velika pomanjkljivost odsotnost lokacije obravnavanih izrazov. Pohvali slovenska imena, ki jih Badjura upošteva na »... sedaj ponemčenih tleh... «. Bohinec se zaveda, da Badjurovo delo mnogih že ustaljenih terminov ne bo moglo izpodriniti, je pa dobro, da so izrazi zbrani, saj bo tako lažje usklajevanje med znanstvenim in ljudskih izrazoslovjem (Bohinec 1953, 330-331).

Ob izidu Badjurove Ljudske geografije se je odzval tudi Svetozar Ilešič, redni profesor na geografskem oddelku ljubljanske univerze. O njej je objavil obširen članek v Geografskem vestniku, v rubriki Književnost. V uvodu je Badjuro najprej označil kot "... enega naših najmarkantnejših planincev ...", ki na svojih poteh zbira ljudska krajevna imena ter izraze in jih objavlja v knjižni obliki. Nadaljuje s samokritiko oziroma kritiko geografije kot stroke, ki ni zmogla zbrati izrazoslovnega gradiva. Navaja številna 
neskladja pri rabi določenih izrazov med geografi in hidrologi (na primer dvojnica podtalnica - talna voda) ter geografi in pedologi (na primer prst - tla). Ilešič pojasnjuje, da je Badjura storil veliko delo, črpal iz različnih virov ter temeljito in s komentarji obdelal mnoga že znana terminološka gesla, dodal pa še veliko novih. Ob vsem poudarja Badjurovo skrb za domač jezik. Ilešič na kratko oriše sistematičen pristop $v$ Badjurovi knjigi in nadaljuje, da bo številna gesla sicer mogoče brez pomisleka umestiti v geografsko terminologijo, vendar se bo o mnogih primerih treba še temeljito pogovoriti. Največ pomislekov izraža na račun številnih arhaizmov in uvajanja pozabljenih zemljepisnih imen, ki so že izginila iz ljudske zavesti. Sporni se mu zdijo tudi nekateri strokovni izrazi, ki jih Badjura kot negeograf vidi na drug način kot na primer geomorfolog (na primer uvajanje izraza dnina namesto kotlina, suha žlebina namesto suha dolina). Ilešič navaja tudi številna krajevna imena in druge toponime, ki jih je Badjura spremenil brez potrebnih argumentov. Kljub pomislekom na koncu Badjurovo knjigo oceni za zelo pomembno in kot temelj za nadaljnje raziskave, avtorju pa tudi čestita za opravljeno delo (Ilešič 1953a, 228-232).

$\mathrm{V}$ isti reviji je Ilešič objavil tudi kratek prispevek o Badjurovem vodniku z naslovom Izbrani izleti po Gorenjskem, Goriškem, Notranjskem, Dolenjskem in Zasavju. Pohvali Badjurov slog pisanja vodnikov, pripomni le, da so izleti morda izbrani preveč "...s stališča Ljubljane in manj iz drugih centrov izletniškega življenja, npr. Maribora. "Največjo vrednost vodnika za geografsko stroko vidi v bogatem imenoslovnem gradivu, žalosti pa ga odsotnost slik in zemljevidov, za kar ne krivi avtorja, pač pa založnika (Ilešič 1953b, 232).

Mnenje o Ljudski geografiji je izrazil tudi Cene Malovrh. V njegovem članku beremo številne pohvale in le redke kritike. Pravi, da je "... Badjurovo delo zaradi bogate vsebine geografiji brus neprecenljive vrednosti... (Malovrh 1953, 618-621). Badjura se je odzval tudi na Malovrhovo kritiko. Podobno kot pri odzivu na Gamsov zapis, je tudi tokrat postregel s številnimi argumenti za vsak izraz, ki mu ga očita Malovrh (Badjura 1954b, 113-119). Svoj odgovor Malovrhu je nadaljeval v Planinskem vestniku, kjer je polemiziral predvsem o izrazu pobočje, ki ga je Badjura na vsak način skušal nadomestiti z izrazom stran (Badjura 1954c, 398-400).

\section{Sodobne obravnave Badjurovega dela}

Po letu 1980 se Badjura in njegovo geografsko delo v literaturi omenjata vsaj petkrat. Geselski članek v Enciklopediji Slovenije je o njem pripravil geograf Milan Orožen Adamič (1987). Poleg poglavitnih poudarkov o življenju Badjure izpostavlja njegov prispevek k vodniški literaturi, pri čemer navaja 8 bibliografskih enot, omenja pa tudi prispevek k smučarski literaturi (dve bibliografski enoti). Konec geselskega članka namenja Ljudski geografiji iz leta 1953 ter ostalim razpravam, v katerih »... je zbral in obdelal veliko krajevnih imen «. Omenjeno je tudi Krajepisno gradivo, ki je ostalo v rokopisu. Dragocen podatek, ki ga v starejših prispevkih ni mogoče zaslediti, je navedba o tem, da je Badjura v okviru Geografskega društva Slovenije za območje Slovenije vodil korekture zemljepisnih imen na topografskih zemljevidih v merilu 1:100.000 (Orožen Adamič 1987, 168).

Leta 1998 je v časopisu Delo Vladimir Habjan v rubriki Znameniti Slovenci objavil članek z naslovom Preromal vso deželo. Večino članka je namenjenega Badjurovemu prispevku k vodniški literaturi, ki jo avtor natančno opiše in omenja devet različnih vodnikov s pripombo, da so nekateri izšli v več izdajah. Vodnike razčleni na izletniške knjige, kjer so opisani večinoma enodnevni izleti, in klasične vodnike. Zadnji del članka nameni opisu Badjurove zapuščine na področju geografske terminologije. Badjuro označi za »... poleg dr. Tume najmarljivejšega zbiralca ljudskih krajevnih, zemljepisnih in drugih izrazov. « Avtor navaja tudi njegov prispevek pri korekturah zemljepisnih imen na topografskih zemljevidih Slovenije, poglavitni del pa nameni ovrednotenju Ljudske geografije. Prikaže tudi težave pri iskanju založnikov za drugi in tretji del omenjene knjige ter ustanove, ki jim je zapustil tipkopise. V sklepu Badjurov bibliografski opus ovrednoti kot »... izredno temeljit in merljiv ter še danes vreden občudovanja ... «(Habjan 1998, 8). 
Širši krog bralcev je z Badjuro in njegovim delom leta 2005 seznanil Dario Cortese, ko je o njem objavil dva članka v reviji Gea, v rubriki Tema meseca.

V članku z naslovom Badjurova krožna pot opisuje pot, ki jo je litijsko planinsko društvo označilo v spomin na svojega rojaka ter zanjo pripravilo vodnik in dnevnik. Cortese omeni še nekatere Badjurove vodnike, dotakne pa se tudi problematike imena Zasavje in ugotavlja, da ga je prvi leta $1928 \mathrm{v}$ istoimenskem vodniku uporabil prav Badjura (Cortese 2005a, 20-27). Drugi članek je namenjen celovitemu orisu življenja in dela Rudolfa Badjure (Cortese 2005b, 16-19).

Slovenska geografska stroka je od leta 2005 bogatejša za Geografski terminološki slovar. Uredniki so v uvodnem delu kritično ovrednotili Badjurov prispevek k slovenski geografski terminologiji. Knjigo Ljudska geografija iz leta 1953 označujejo kot »... povzetek obsežnejšega rokopisa, nastalega med letoma 1938 in 1946. «Po njihovem mnenju je Badjura pogosto pretiraval in že uveljavljene geografske izraze nadomeščal z ljudskimi, da bi jih tako ohranil v jezikovnem spominu. Ugotavljajo tudi, da je Badjuri to mnogokrat uspelo, zato so nekateri ljudski izrazi vključeni tudi v slovar (Kladnik, Lovrenčak in Orožen Adamič 2005, 8-9).

\section{Sklep}

Izredna skrb za ustrezno rabo slovenskega jezika, slovenskih zemljepisnih imen in strokovnih izrazov, ki jo je Badjura izkazoval v svojih temeljnih delih, se zrcali tudi v njegovih krajših prispevkih.

Že leta 1913 je objavil pomislek o primernosti imenovanja planinskih koč (Badjura 1913b, 75), leta 1954 razpravo o Nemškem vrhu oziroma Visoki vrtači v Karavankah kot odmev na kritiko tega poimenovanja, ki jo je izrazil Josip Šašel (Badjura 1954d, 442-447), leta 1955 razpravo o poimenovanju soteske Kavčka (Kavčičje) pri Mostah (Badjura 1955b, 124-127), leto pozneje pa o pojmu poljica in lastnem imenu, ki izhaja od tod (Badjura 1956a, 32-35; Badjura 1956b, 102-105) in čez nekaj let o imenu Jermanova vrata (Kamniško sedlo) (Badjura 1961, 35-37). Vsa ta prizadevanja izkazujejo skrb za pravilen zapis in ohranjanje domačih zemljepisnih imen ter njegovo kleno držo in vztrajnost, ne glede na številne kritike, ki jih je bil deležen.

V strokovnih krogih je njegovo delo precej odmevalo, predvsem ob izidu Ljudske geografije (na primer Borko 1953; Gams 1953; Bohinec 1953; Ilešič 1953a; Malovrh 1953), med laično javnostjo pa je bil znan predvsem po številnih turističnih vodnikih.

Na sodobno zemljepisno imenoslovje in terminologijo je razen z že omenjenimi pisnimi deli vplival tudi z gradivom iz svoje obširne kartoteke imen, gradivom za izpopolnitev Pleteršnikovega slovarja ter korekturami zemljepisnih imen na topografskih zemljevidih v merilu $1: 100.000$, ki jih je vodil v okviru Geografskega društva Slovenije (Brilej 1952, 44; Orožen Adamič 1987).

Kljub nekaterim utemeljenim pripombam, kot je na primer očitek, da posamezni tlopisni izrazi v Ljudski geografiji niso lokacijsko opredeljeni (Gams 1953; Ilešič 1953a), ima delo Rudolfa Badjure za sodobno geografsko raziskovanje neprecenljiv pomen. Številni na terenu zbrani izrazi so dandanes med domačini že pozabljeni in prav Badjurova dela nam lahko pomagajo pri odstiranju tančice skrivnosti pokrajine v preteklosti. Zaradi obsežnega dela, ki ga je Badjura opravil na področjih, s katerimi se ukvarjamo geografi, ga lahko opredelimo za pomembnega ustvarjalca $\mathrm{v}$ »naših« vrstah.

\section{Viri in literatura}

Badiura, R. 1909a: Križna jama. Dom in svet 22-1. Ljubljana.

Badiura, R. 1909b: Pot čez Veliko Planino v Bistrični Konec nad Kamnikom. Dom in svet 22-10. Ljubljana. Badiura, R. 1921: Pozimi v Kamniške planine! Planinski vestnik 22-1. Ljubljana.

Badiura, R., Brinšek, B. 1908a: Izlet na Kamniško sedlo. Planinski vestnik 14-1. Ljubljana. 
Badiura, R., Brinšek, B. 1908b: Nove jame ob Cerkniškem jezeru. Planinski vestnik 14, 6-7. Ljubljana. Badjura, R. 1908: Okrešelj v Savinjskih planinah. Dom in svet 21-9. Ljubljana.

Badjura, R. 1913a: Na Triglav, v kraljestvo Zlatorogovo! Ljubljana.

Badjura, R. 1913b: Zemljevid slovenske zemlje. Planinski vestnik 19-4. Ljubljana.

Badjura, R. 1927: Šmarnogorska grmada. Planinski vestnik 28-6. Ljubljana.

Badjura, R. 1950: Slovensko in nemško geografsko sedlo. Geografski vestnik 22. Ljubljana.

Badjura, R. 1951: Gorski prehodi v luči ljudske geografije. Ljubljana.

Badjura, R. 1953: Ljudska geografija: Terensko izrazoslovje. Ljubljana.

Badjura, R. 1954a: K problemu slovenskega geografskega izrazoslovja. Naši razgledi 3-1. Ljubljana.

Badjura, R. 1954b: Ljudska geografija (Terensko izrazoslovje). Planinski vestnik 10-2. Ljubljana.

Badjura, R. 1954c: Ljudska geografija (Terensko izrazoslovje). Planinski vestnik 10-7. Ljubljana.

Badjura, R. 1954d: Nemški vrh $2180 \mathrm{~m}$ ali Visoka vrtača? Planinski vestnik 10-8. Ljubljana.

Badjura, R. 1955a: Topografični oris 430 gorskih prehodov v Sloveniji. Ljubljana.

Badjura, R. 1955b: Nova pisarija. Planinski vestnik 11-3. Ljubljana.

Badjura, R. 1956a: Dve vrsti topografičnih polic. Planinski vestnik 12-1. Ljubljana.

Badjura, R. 1956b: Dve vrsti topografičnih polic. Planinski vestnik 12-2. Ljubljana.

Badjura, R. 1957: Ljudska geografija: Terensko izrazoslovje, Rešeto umetnih in ljudskih zemljepisnih izrazov. Ljubljana.

Badjura, R. 1961: Jermanova vrata (1921 m). Planinski vestnik 17-1. Ljubljana.

Badjura, R. 1963: Krajepisno gradivo: Dodatki k Ljudski geografiji 1953. Ljubljana.

Bohinec, V. 1953: Rudolf Badjura, Ljudska geografija. Slovenski etnograf 6-7. Ljubljana.

Borko, B. 1953: Badjurova »Ljudska geografija«. Ljubljanski dnevnik 130. Ljubljana.

Brilej, A. 1952: Ob 70 letnici Rudolfa Badjure. Planinski vestnik 52-1. Ljubljana.

COBISS, Kooperativni online bibliografski sistemi in servisi. Medmrežje: http://www.cobiss.si/ (13.2.2014).

Cortese, D. 2005a: Badjurova krožna pot - veliki zasavski treking. Gea 15-6. Ljubljana.

Cortese, D. 2005b: Rudolf Badjura: »Kranjska banska uprava za moje delo ni imela dosti smisla.« Gea 15-6. Ljubljana.

Gams, I. 1953: K problemu slovenskega geografskega izrazoslovja. Naši razgledi 2-21. Ljubljana.

Habjan, V. 1998: Preromal vso deželo: znameniti Slovenci - Rudolf Badjura. Delo 40-216. Ljubljana.

Ilešič, S. 1953a: Rudolf Badjura, Ljudska geografija. Geografski vestnik 25. Ljubljana

Ilešič, S. 1953b: Rudolf Badjura, Izbrani izleti po Gorenjskem, Goriškem, Notranjskem, Dolenjskem in Zasavju. Ljubljana.

Kladnik, D., Lovrenčak, F., Orožen Adamič, M. (ur.) 2005: Geografski terminološki slovar. Ljubljana. Kocutar, S. 2009: Rudolf Badjura, pisec prvih slovenskih turističnih vodnikov. Maribor.

Malovrh, C. 1952: Rudolf Badjura, Gorski prehodi v luči ljudske geografije. Geografski vestnik 24. Ljubljana. Malovrh, C. 1953: Ljudska geografija. Planinski vestnik 8-10. Ljubljana.

Melik, A. 1932: Rudolf Badjura, Izleti po Karavankah. Geografski vestnik 8-1. Ljubljana.

Orožen Adamič, M. 1987: Badjura Rudolf. Enciklopedija Slovenije 1. Ljubljana.

Slovar slovenskega knjižnega jezika. Ljubljana, 1985.

Slovar slovenskega knjižnega jezika. Ljubljana, 2000.

Slovenski biografski leksikon 1925-1991. Medmrežje: http://www.slovenska-biografija.si/oseba/sbi132759/ (12.2.2014).

Snoj, M. 1997: Slovenski etimološki slovar. Ljubljana.

Tovšak, S. 2010: Rudolf Badjura, pisec prvih slovenskih turističnih vodnikov, katalog k istoimenski razstavi. Arhivi 33-1. Ljubljana.

Vrišer, I. 2002: Uvod v geografijo. Ljubljana. 


\section{Summary: The complete geographical works of Rudolf Badjura}

(translated by Tina Potočnik Rodriguez)

Rudolf Badjura (1881-1963) is primarily known as a tourist and sports writer, as a reference for tourism and a collector of local features and attractions; only rarely is he identified as a geographer. In the textbook Uvod v Geografijo (»Introduction to Geography«) Badjura is described as a geographer; an amateur who, like Henrik Tuma, was engaged in toponomastics. His work Ljudska geografija (»Folk Geography «) is also cited in the book's list of recommended literature on toponomastics. This is clearly insufficient, however, for ensuring that geographers, especially the young generation, are acquainted with his contribution to geography.

Badjura definitely deserves a place in the annals of geography for his work Ljudska geografija - Terensko izrazoslovje (»Folk Geography - Field Terminology«). In it, he skillfully intertwines two leading ideas: Slovenian geographical terminology, with special focus on superficial forms, andgeographic onomastics. The content is divided into six chapters. The book -both a geomorphology textbook and a terminological dictionary- is one of the fundamental works on onomastics and, as such, of great help to present-day researchers who are investigating toponyms, choronyms (names of landscape units) and other geographical names. At the time of its release, the book received considerable commentary among geographers, many of them offering more or less constructive criticism. In response, in 1957 Badjura wrote the second part of the book, which he subtitled Rešeto umetnih in ljudskih zemljepisnih izrazov (»The Sieve of Artificial and Folk Geographical Names"). In it, he not only provides well-founded answers to the criticism of Ljudska geografija (»Folk Geography«) but also introduces many corrections for the mistakes that crept into the first book. Badjura did not manage to find a publisher for his second work, which therefore remained in typescript form. This explains why it received hardly any response from the geographical profession. Ten years after the first part of Ljudska geografija (»Folk Geography«) was published, Badjura prepared a third part called Krajepisno gradivo - dodatki k Ljudski geografiji (1953), or in English, »Topographical Material - Additions to Folk Geography (1953)«. In this work, he further improves and provides additional explanations for some specialized geographical terminology which appeared in the first two pieces and the typescript of Topografični oris 430 gorskih prehodov po Sloveniji (»A Topographical Outline of 430 Mountain Passes across Slovenia «). In addition, he presents some corrections for the above-mentioned works. Unfortunately, Badjura's third piece from the Ljudska geografija (»Folk Geography«) series suffered the same fate: it was not published, thus remaining in typescript form only.

Badjura studied mountain passes and their names in an extremely detailed and committed way. It struck him that the term sedlo (Slovenian for saddle, in the geographical sense), which he believed was a translation of the German expression der Sattel (this is rejected by present-day etymologists), had become widely used in Slavic terminology. Based on his own observation, Badjura claimed that the Slovenian term sedlo traditionally denoted a concept which was quite distinct from the meaning of the German word. He published three works on this topic, in 1950 an article entitled Slovensko in nemško geografsko sedlo (»The Slovenian and German Geographic Saddle»), a year later an independent booklet called Gorski prehodi v luči ljudske geografije (»Mountain Passes in the Light of Folk Geography), followed by a typescript of Topografični oris 430 gorskih prehodov po Sloveniji (»A Topographical Outline of 430 Mountain Passes across Slovenia «). In the first article he explains that, according to his research, the Slovenian word sedlo denotes a place in a mountain pasture where herders settled with their herds and build huts for themselves, or an exposed area where they could sit and watch their animals. According to Badjura, in some inhabited mountain areas, sedlo can also refer to a subdivision of a piece of land. Badjura proposes 27 different folk expressions that could be used in place of the term sedlo for naming mountain passes.

Badjura was probably best known in lay society for his numerous guides published throughout his fruitful career, starting with a 1913 guide entitled $\mathrm{Na}$ Triglav, v kraljestvo Zlatorogovo (»To Mount Triglav, the Kingdom of the Goldhorn«), which describes the ascent to Slovenia's highest mountain, still in the 
context of the Austro-Hungarian Monarchy. His guides present the whole Slovenian territory, with the exception of Primorje (the Slovene littoral), which belonged to Italy, and Koroška (Carinthia), which became part of Austria following a plebiscite in 1920. The majority of Badjura's guides are in small, pocket-sized format. In terms of the content, they are normally divided into a general part with general information for the reader on the individual region, its characteristics, bus and train timetables, holiday and health resorts, and a topographical section (so named by Badjura) containing different routes in the region, with places and other attractions along them described in more detail.From today's perspective, Badjura's lists of places, found at the end of each booklet, are also of great value. They enable toponymic research of Slovenian and foreign geographical names. Most guidebooks contain maps which reflect Badjura's care in recording the features that are important for tourism, especially roads, accommodation and other objects. Badjura was also very consistent in his use of Slovenian geographical names in areas of the neighbouring countries, especially Austria and Italy.

Badjura's work also received considerable response from Slovenian geographers, their first reaction dating back to 1932. Anton Melik, lecturer at the Department of Geography in Ljubljana at that time, published a report on Badjura's guidebook called Izleti po Karavankah (»Trips along the Karawanks «) in the literary section of the geographical journal Geografski vestnik. As well as providing a brief general description of the booklet, which he refers to as a signpost book «, he also emphasizes Badjura's conclusions as to the open toponymic questions of this mountain world and the cross-border nature of the guidebook, which he perceives as essential for tourism. It was Badjura's Ljudska geografija (»Folk Geography«), however, that attracted the most attention. Already in the year of its publication, Ivan Gams, at that time employed at the SAZU Geographical Institute, commented on it in the Naši razgledi newspaper, as did Valter Bohinec, from the National and University Library in Ljubljana, in the Slovenski etnograf journal under the section dedicated to book reviews and assessments. Also in the same year, Svetozaver Ilešič, professor at the Department of Geography, Faculty of Arts, in Ljubljana, reviewed the book in the geographical journal Geografski obzornik.

After 1980, Badjura and his geographical works appear in other literature at least five times. Milan Orožen Adamič prepared an article on him in the Encyclopedia of Slovenia (1987). In addition to providing fundamental information on Badjura's life, Orožen Adamič emphasizes Badjura's contribution to guidebook literature, quoting 8 bibliographic units, and cites his contribution to the field of ski literature (2 bibliographic units). At the end of this article, he points to Ljudska geografija (»Folk Geography«) dating back to 1953, and to other discussions, where »... [Badjura] collected and worked on a number of toponyms ...«. Krajepisno gradivo (»Topographical Material«), left in typescript form, is mentioned as well. In addition, Orožen Adamič includes an important piece of information that cannot be found in previous works, namely that, as part of Badjuras' activities in the Geographical Society of Slovenia, he was responsible for correcting the geographical names in the area of Slovenia, on topographic maps with a scale of $1: 100,000$.

Moreover, Badjura contributed some non-technical material to the Delo newspaper and Gea magazine. His work was also assessed in the introductory part of the Dictionary of Geographical Terms (2005; Geografski terminološki slovar) by the editors.

The exceptional concern he showed in his fundamental works for the appropriate use of the Slovenian language, Slovenian geographic names and technical expressions can also be perceived in his shorter contributions. Badjura further influenced modern geographic onomastics and terminology with material from his extensive record of names, his material for the improvement of Pleteršnik's dictionary and the corrections of geographic names on topographic maps with a scale of 1:100,000, which he led in connection with the Geographic Society of Slovenia. 